\title{
Amacompri information system for postpartum nursing monitoring
}

\section{Sistema de información Amacompri para el seguimiento de enfermería posparto}

\author{
Carolina Vargas-Porras ${ }^{1,2}$, Emilio Justiniano Cárcamo-Troconis ${ }^{1} \mathcal{\odot}$, Carme Ferré-Grau ${ }^{2}$, María \\ Inmaculada de Molina-Fernández ${ }^{2}$. \\ ${ }^{1}$ Universidad Industrial de Santander, Bucaramanga, Colombia. \\ 2 Universitat Rovira i Virgili, Tarragona, España.
}

*Dirigir correspondencia a: carvarpo@uis.edu.co

\begin{abstract}
Proceso Editorial
Recibido: 120721

Aceptado: 140921

Publicado: 161121

\section{ABSTRACT}

Background: First-time mothers require greater nursing accompaniment in the postpartum period due to their lack of expertise and preparation for the new challenges of motherhood. Information and communication technologies (ICTCs) allow easy access to learning habits for the transition into motherhood; however, the lack of technological appropriation for postpartum monitoring becomes evident in developing countries and in the Western world. Methods: This study developed the Amacompri postpartum nursing tracking information system, which is based on Mercer's theory of becoming a mother and discusses the vital environment: First-time mother's family and friends. The Amacompri software was designed using the SCRUM methodology, java web technologies and PostgreSQL database. Results: This information system features a web version and a mobile App. The technical validation involved 10 experts, and the validation by population 10 first-time mothers. This first group reviewed the quality of presentation and content in the early stages of the software. Finally, the Amacompri system was used for 4 months by 33 first-time mothers, who evaluated the application for design, usability, and applicability. Amacompri software was effective for non-face-to-face nursing accompaniment to first-time mothers. Conclusions: The Amacompri software was designed based on Mercer's theory of becoming a mother, and has been technically validated (experts) and validated by population (first mothers), demonstrating its quality in both presentation and content. Its evaluation demonstrated its effectiveness in meeting the development objective. In this context, the Amacompri software meets multimedia requirements in the functional, technical-esthetic, and pedagogical aspects.

Keywords: Information Systems; Mobile Applications; Nursing Care; Postpartum Period;
\end{abstract}

DOI 10.17081/innosa.141

(C) Copyright 2021

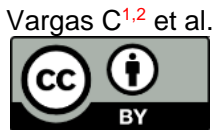
Software

\section{INTRODUCTION}

Women in transition to motherhood, especially first-time mothers, experience high vulnerability, because of the new challenges they face and for which they are ill prepared (1-3). These challenges include contradictory feelings before pregnancy: Fear, uncertainty, guilt or failed lactation and too many information available on the internet. For this, first-time mothers require greater accompaniment in the postpartum stage $(4,5)$. The use of technological advances in healthcare has shown benefits and facilitates monitoring to support first-time mothers, as noted in previous studies (6-8) in which the use of mobile applications have allowed for greater access to learning, especially if these technologies are focused on user needs (9). 
In Singapore, Shorey has demonstrated the effectiveness of technology to support first-time mothers in the postpartum period, based on Bandura's self-efficacy theory (10-13); however, in the Western world there is little experience with postpartum follow-up using technologies $(6,14,15)$. In fact, no software specifically oriented to providing nursing support to first-time mothers in the transition to motherhood has been found in the literature. Therefore, the objective of this study was to design, validate and evaluate an information system for postpartum nursing monitoring, based on Mercer's theory.

\subsection{Theoretical framework for the development of the information system}

The design of the information system for postpartum nursing monitoring was guided by Ramona Mercer's middle-ranking theory titled "Becoming a Mother" based on nursing research on the effectiveness of interventions aimed at fostering such a transition. Mercer used Bronfenbrenner's concept of nested interaction in living environments: Family, friends, community, and society, where interactions between mother, child and father are at the center of the environments (16).

This model of vital environments describes what facilitates or inhibits the process of becoming a mother and presents environment variables and maternal-child characteristics, which must be considered for nursing practice and research (1).

Given the complexity of the construct of becoming a mother, and that not all factors can be covered in the same study, it was decided to work with the living environment: Family and friends. This interaction environment includes continuity of cultural customs, family continuity, knowledge and skills, physical and social support, and affirmation as a mother. In addition, this environment is the most influential in promoting the process of becoming a mother $(16,17)$.

\section{METHODS}

\subsection{Amacompri software design}

For software development, the SCRUM methodology was chosen for its extensive use, robustness and structure, and because it allows for agile progress, advance deliveries, productivity gain, flexibility and project quality (18). SCRUM works on iterations divided by work packages that culminate in an integrated application.

The first process was the analysis of requirements based on the proposed objectives, creating an overview of the software to be modeled. This analysis defined functional and non-functional requirements, the use case and activity diagrams, data modeling, and information system modules were also designed. Three user profiles were identified: System administrator, nurse, and first-time mothers.

In the second process based on functional requirements, the relationship between the functionalities for each actor involved in the system was classified (Figure 1). In the third process, the order of priorities for implementing capabilities was planned based on project dependencies, relevance, and complexity, with the most complex and low-dependency activities being developed first. In the fourth process work packages were defined according to the system level access obtaining as a result the to-do list and schedule of activities. Finally, the desired capabilities in each work package were implemented and tested. 
Figure 1. Amacompri software architecture

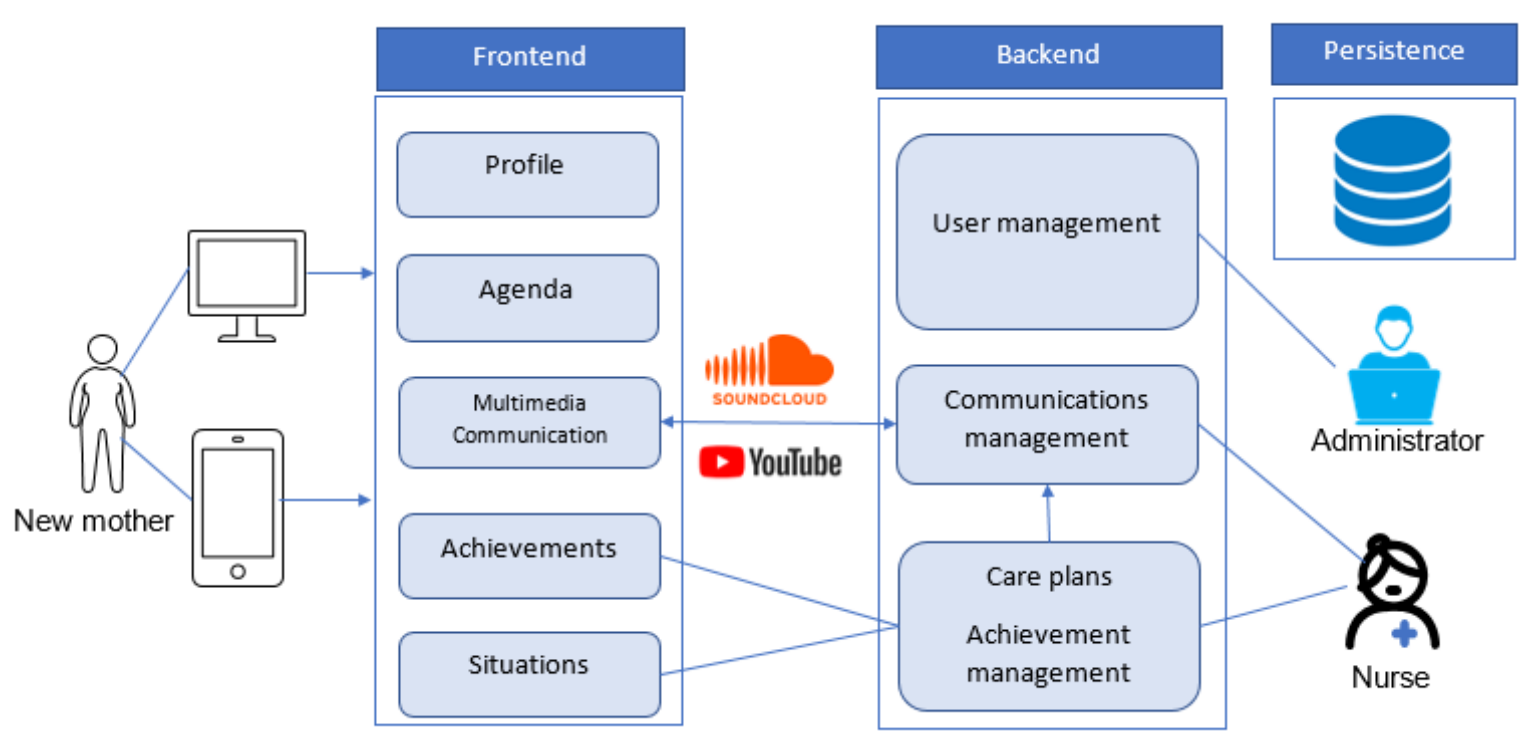

Source: authors' elaboration

The software was called Amacompri, which refers to "Mother support to become a first-time mother", is based on Mercer's theory and focuses on promoting social support, affective bonding, maternal self-efficacy and maternal role, which are concepts supported by the scientific literature as highly influential in the process of becoming a mother. The review of the scientific literature and consultation was carried out by a panel of 5 experts (2 with Master's degrees and 3 with PhDs in Nursing).

\subsection{Software Architecture}

The Amacompri software was developed using Java Web and PostgreSQL database technologies, with the Model-View-Controller design pattern (19). At the architecture level, the Java Server Faces, EJB, and JPA scheme were used to differentiate data presentation (frontend), business logic (backend), and data persistence layers. As a web server solution, Jboss was chosen for performance, stability and use at the University where the information system was hosted.

\subsection{Data structure}

The minimum basic data set (NMDS) proposed by Werley and Lang (1998) was used for information recording, which establishes an initial framework for identifying and implementing the dataset representing the core components of nursing practice (20). Additionally, standardized nursing languages (SNLs) were used to unify labels to identify diagnostics, interventions, and outcomes in nursing care.

For first-time mother situations recordings, Amacompri software included two basic categories of NMDS: Mother and baby demographics. Unstructured data such as the mother's profile are also collected and can be found in Table 1. Amacompri software stores in a database the data generated by the first mother's situations entries, which is analyzed and reviewed by the nurse who defines the care plans (Figure 1). 
Table 1. Amacompri Collected Data

\begin{tabular}{|l|l|}
\hline \multicolumn{1}{|c|}{ Data Type } & \multicolumn{1}{|c|}{ Collected data } \\
\hline NMDS & $\begin{array}{l}\text { Name } \\
\text { Age } \\
\text { Marital status } \\
\text { Baby's gender }\end{array}$ \\
\hline NANDA Taxonomy & $\begin{array}{l}\text { Diagnostics } \\
\text { Characteristics }\end{array}$ \\
\hline NIC Taxonomy & Interventions and activities \\
\hline NOC Taxonomy & Results \\
\hline Situations & $\begin{array}{l}\text { Subject } \\
\text { Degree of affectation }\end{array}$ \\
\hline Achievements & $\begin{array}{l}\text { Feeling } \\
\text { Mother and baby alarm signs }\end{array}$ \\
\hline Others & Initial and Final Rating \\
\hline & $\begin{array}{l}\text { Nursing notes } \\
\text { First-time mother profile } \\
\text { Description of the situation }\end{array}$ \\
\hline & Thoughts and behaviors \\
& Mother's notes \\
Amacompri Reviews
\end{tabular}

Source: authors' elaboration

\subsection{Data Security}

To ensure the integrity and security of Amacompri's data, the web server backup and security policies defined by the Division of Information Services attached to the University were used. The application was accessed using high-security password access control and role-by-role feature restriction.

The password in the database is protected by the SHA 1 (21) algorithm, creating a security barrier, even if there is direct access to the data. The application controls access through user's privileges, so it ensures that only the data defined for each profile are accessed. Authentication and authorization are different concepts, the user can successfully authenticate to the system, but is not authorized to query all the information.

To maintain the database integrity, no information about the user's history is deleted, only enabled or disabled. Likewise, the database has been validated with the design standards of the University, allowing for managing referential integrity.

\subsection{Standardized Language}

To record first-time mother situations, the nurse establishes each mother's care plan using the standardized nursing language (diagnostics, interventions, and nursing results) built into the Amacompri software.

\subsection{Multimedia Integration}

The software development is linked to the audiovisual material design, composed of 26 thematic audios made by experts, 4 support videos and an exclusive motivational musical piece for Amacompri that identifies the experience of new mothers and gives music to the follow-up. 


\subsection{Amacompri Software Validation and Evaluation Process}

The software was validated and evaluated in Colombia. For software validation, an intentional non-probabilistic sampling was made including 10 experts and 10 first-time mothers. The software was evaluated by 33 first-time mothers from a randomized controlled trial (22).

The experts were selected based on their curriculum vitae available on the website of the Ministry of Science Technology and Innovation of Colombia and then were sent a letter inviting them to. The 10 experts were 3 perinatal nurses, 1 health education and communication nurse, 1 public health and epidemiology nurse, 1 spiritual care nurse, 1 psychologist, 2 social communicators and 1 multimedia designer. In the second round of validation, 3 different experts participated:1 perinatal maternal nurse, 1 mental health and educational communication nurse, 1 systems engineer.

The mothers participating in the validation and evaluation of the software were recruited from the postpartum and outpatient service of Maternal-child health care center in Colombia. The inclusion criteria were: First-time mothers with ages 18 years and older with partner, healthy singleton child 4 months or younger, with a mobile phone with internet access. The exclusion criteria were multiple pregnancy, illiteracy, mental or behavioral disorders or other morbidities. The distribution of the mothers according to educational level, socioeconomic level, marital status and age can be seen in Figure 2.

For validation and evaluation, "the cataloging and multimedia evaluation sheet" of Pere Marqués was used. This instrument evaluates in detail the functional, technical-esthetic and pedagogical aspects, using the following scale: Excellent, high, correct, and low. Finally, an overall assessment was established and the evaluator's supplementary observations were recorded (23).

One month after the development of the Amacompri software, the instrument was applied to technical validation (experts) and validation by population (first mothers). Subsequently, a panel of 3 different experts analyzed the observations recorded in the validation and the software was adjusted and improved by consensus of agreements greater than 50\%. Finally, this validated version of the Amacompri software had an evaluation by a group of 33 first-time mothers who used the software from the first week to the 4 postpartum months (22).

Figure 2. Distribution of mothers according to marital status, age, educational and socioeconomic level

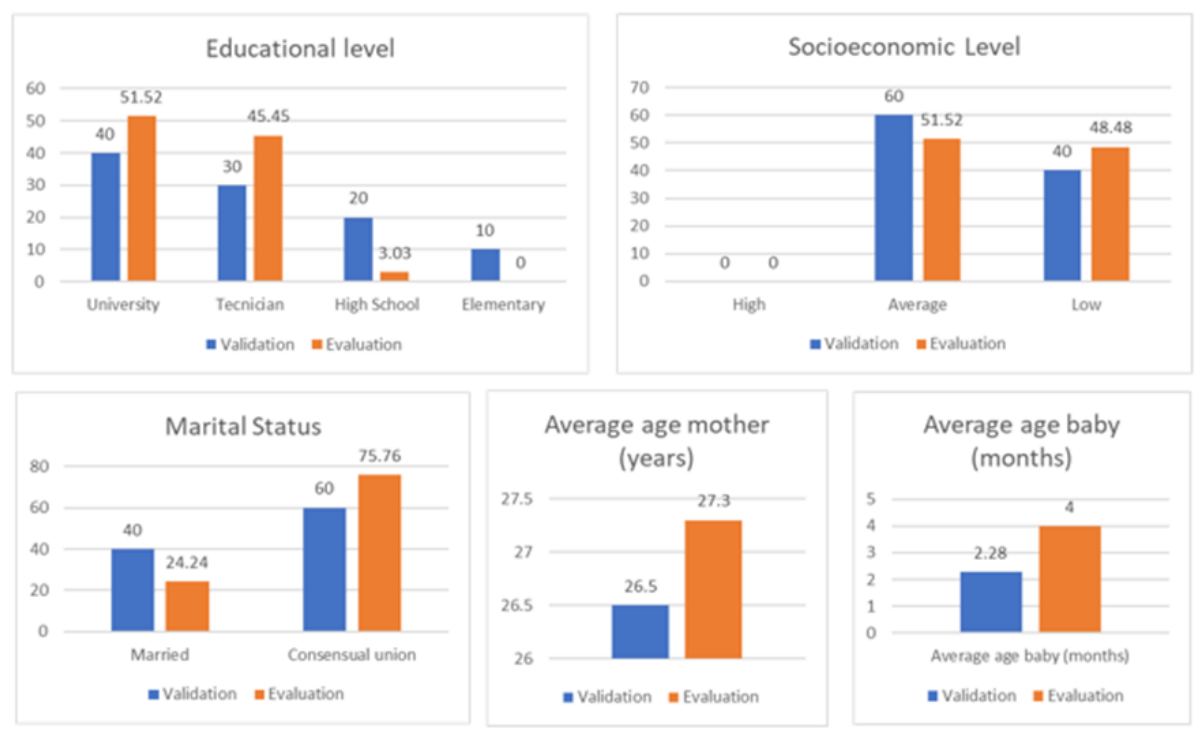

Source: authors' elaboration 
2.8. Ethical aspects. This study conformed to the Helsinki Declaration and Resolution 008430 of 1993 of the Colombian Ministry of Health, which sets forth the standards for health research. The research was approved by the Bioethics Committee of Maternal-child health care center in Colombia on April 4, 2018 (reference 00418). All participants gave their informed consent in writing.

\section{RESULTS}

The Amacompri software modules were organized according to Mercer's vital environment: Family and friends. The audiovisual material included 2 videos about Amacompri, 1 song of motivation and recognition for first-time mothers, 26 thematic audios made by experts, and 4 videos of a first-time mother supporting other mothers. These materials are original and were created for the exclusive use of the software according to Mercer's theoretical reference (16) (Table 2).

The audiovisual production in Amacompri was integrated using the Soundcloud platform for expert audios and YouTube for videos. This interaction allowed for the distribution of bandwidth-associated loads, content storage and processing, and the leverage of consolidated media streaming development for a better user experience. With 2 versions of Amacompri, a mobile app and a web version, it was possible to adapt the tool to the specific needs of first-mothers, from those that only have a smartphone or those that prefer to browse information in a computer or tablet (Figure 3).

Table 2. Amacompri software modules and content according to a vital environment: Family and friends. Environment Interaction according to Mercer

\begin{tabular}{|c|c|c|}
\hline $\begin{array}{l}\text { "Becoming a Mother" } \\
\text { Theory Vital environment: } \\
\text { Family and friends }\end{array}$ & $\begin{array}{l}\text { Software } \\
\text { Modules }\end{array}$ & Content \\
\hline \multirow{2}{*}{$\begin{array}{l}\text { Continuity of cultural } \\
\text { customs }\end{array}$} & Home & Main Menu, Motivating Phrases, Messaging. \\
\hline & Profile & Mother and Baby Data, Photo \\
\hline $\begin{array}{l}\text { Family continuity } \\
\text { Knowledge and skills }\end{array}$ & Mother kit & $\begin{array}{l}\text { Software and official song presentation. } \\
\text { Audios from thematic experts: Care of the mother in the } \\
\text { postpartum period, care of the newborn, breastfeeding, } \\
\text { social support, relationship - sexuality, bond, } \\
\text { postpartum mood-depression, positive baby rearing, } \\
\text { maternal self-efficacy, maternity. } \\
\text { First-time mother videos: Social support, affective bond, } \\
\text { maternal self-efficacy, maternal role. }\end{array}$ \\
\hline \multirow[t]{2}{*}{ Affirmation as mother } & My space & $\begin{array}{l}\text { Record mother or baby situations. Alarm signs, } \\
\text { thoughts, actions, degrees of involvement and feelings } \\
\text { are recorded. } \\
\text { The nurse can record the care plan, select diagnostics, } \\
\text { interventions, activities and nursing outcomes and } \\
\text { tracks the consultation and send alerts to mothers. }\end{array}$ \\
\hline & $\begin{array}{l}\text { Assessment } \\
\mathrm{s}\end{array}$ & $\begin{array}{l}\text { Includes the creation of achievements, categories, } \\
\text { prizes/user score and the design of assessments. }\end{array}$ \\
\hline Physical and social support & & $\begin{array}{l}\text { Messaging center for two-way communication between } \\
\text { nurse and mother. } \\
\text { First-time mothers have an agenda scheduler and a } \\
\text { diary to write what happens to them on a day-to-day } \\
\text { basis. }\end{array}$ \\
\hline
\end{tabular}




\begin{tabular}{|l|l|l|}
\hline $\begin{array}{c}\text { "Becoming a Mother" } \\
\text { Theory Vital environment: } \\
\text { Family and friends }\end{array}$ & \multicolumn{1}{|c|}{$\begin{array}{c}\text { Software } \\
\text { Modules }\end{array}$} & Content \\
\hline \multicolumn{1}{|l|}{} & $\begin{array}{l}\text { The nurse has an agenda to schedule her home visits } \\
\text { and telephone follow-ups. }\end{array}$ \\
\hline & Reports & $\begin{array}{l}\text { Report of users served, evaluations and achievements, } \\
\text { nursing diagnostics, situations and notes. }\end{array}$ \\
\hline & $\begin{array}{l}\text { General } \\
\text { parameters }\end{array}$ & Software users, nursing diagnostics. \\
\hline
\end{tabular}

Source: authors' elaboration

The Amacompri information system enabled the integration of standardized nursing language (diagnostics interventions and nursing results) for the postpartum follow-up of each first-time mother The nurse established the care plan individually, using Mercer's theoretical concepts.

In its validation by first-time mothers and experts, the Amacompri software obtained mostly high marks (Table 3). Both groups highlighted the importance of the software as an instrument to support first-time mothers online by a nurse. They also considered that the material was interesting and responded to the needs of a mother after childbirth. They described it as easy to access, easy to use and innovative and as an improvement they proposed the use of stronger contrast colors.

Figure 3. Amacompri Software: Situations, care plan, evaluation, and my space

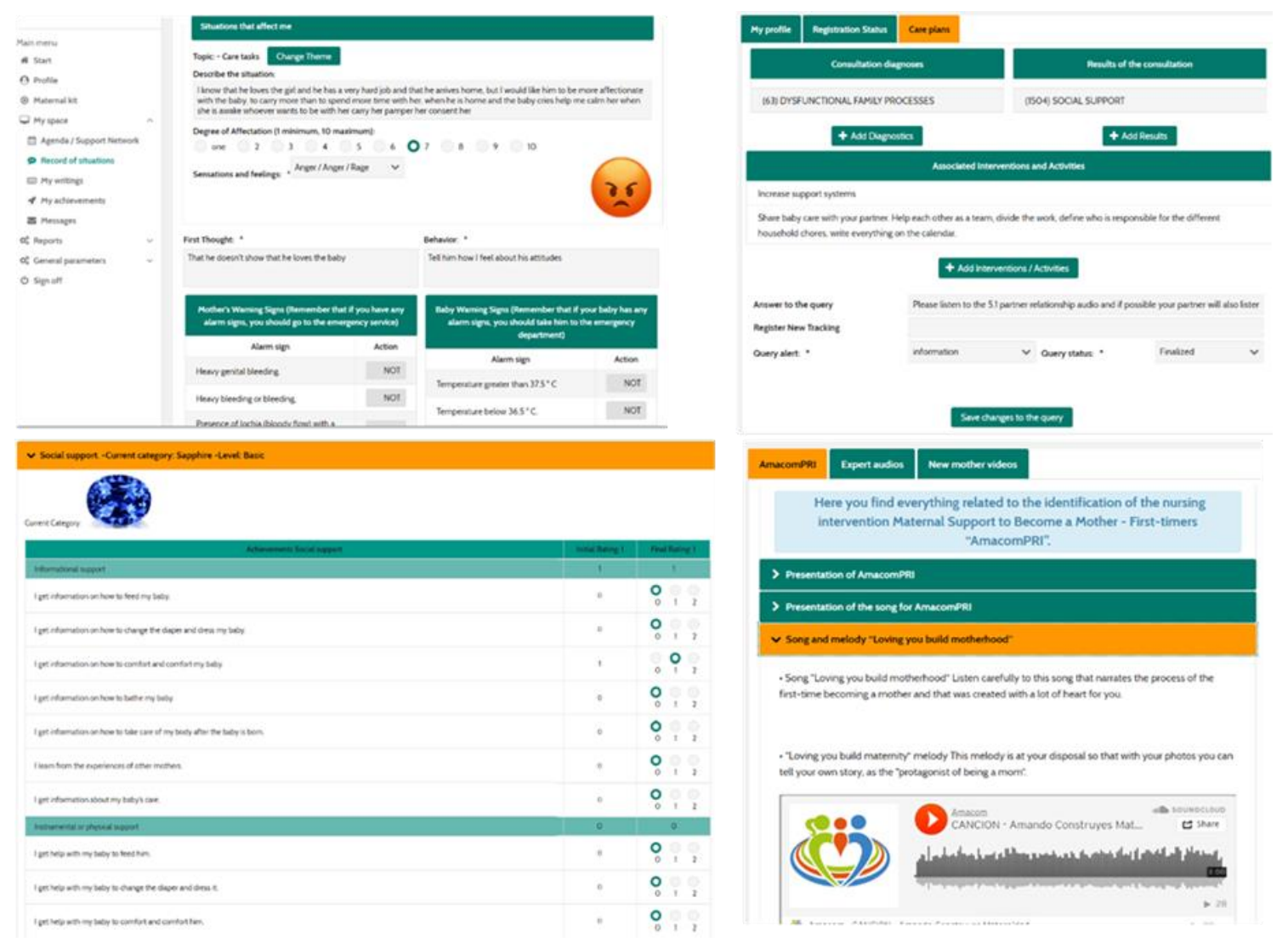

Source: authors' elaboration 
Table 3. Amacompri information system validation and evaluation

\begin{tabular}{|c|c|c|c|c|c|c|c|c|c|c|c|c|}
\hline \multirow{3}{*}{$\begin{array}{l}\text { Global } \\
\text { valuation }\end{array}$} & \multicolumn{8}{|c|}{ Validation } & \multicolumn{4}{|c|}{ Evaluation } \\
\hline & \multicolumn{4}{|c|}{$\begin{array}{l}\text { Validation by population } \\
n=10 \text { new mothers }\end{array}$} & \multicolumn{4}{|c|}{$\begin{array}{l}\text { Technical validation } \\
n=10 \text { experts }\end{array}$} & \multicolumn{4}{|c|}{$\begin{array}{l}\text { Assessment by population } \\
n=33 \text { new mothers }\end{array}$} \\
\hline & $E \%$ & $\mathbf{H} \%$ & C \% & L \% & $E \%$ & $\mathbf{H} \%$ & C \% & L \% & $E \%$ & $\mathbf{H} \%$ & C $\%$ & L \% \\
\hline $\begin{array}{c}\text { Functional } \\
\text { aspects } \\
\text { Utility }\end{array}$ & 75 & 22.5 & $\begin{array}{c}2.5 \\
0\end{array}$ & 0.0 & 83.33 & 15.84 & 0.83 & 0.0 & 79.55 & 16.41 & 4.04 & 0.0 \\
\hline $\begin{array}{l}\text { Technical } \\
\text { and } \\
\text { aesthetic } \\
\text { aspects }\end{array}$ & 83.75 & 6.25 & 10 & 0.0 & 72.5 & 22.5 & 5 & 0.0 & 89.02 & 10.61 & 0.37 & 0.0 \\
\hline $\begin{array}{l}\text { Pedagogical } \\
\text { aspects }\end{array}$ & 77.27 & 19.73 & 3 & 0.0 & 81 & 18 & 1 & 0.0 & 86.37 & 13.34 & 0.30 & 0.0 \\
\hline
\end{tabular}

E: Excellent; $\mathbf{H}$; High; C: Correct; L: Low

Functional aspects. Usefulness: Teaching effectiveness, relevance, ease of installation, teaching versatility, multiple external links, two-way communication channels, documentation, online support services, credits, absence of advertising.

Technical and esthetic aspects: Audiovisual environment, multimedia elements, content quality and structuring, structure and navigation of activities, hypertexts, interaction, reliable execution, speed, originality and use of advanced technology.

Pedagogical aspects: Specification of objectives, motivational capacity, users and recipients adaptation, resources to search and process data, potential of didactic resources, tutoring and evaluation, application / creative approach, promoting self-learning, facilitates cooperative work.

Source: authors' elaboration

The experts highlighted the originality, innovation and functionality of this software that allowed for interaction between a first-time mother and a nurse through audiovisual materials of excellent quality and effective communication, and allowed the nurse, doing online postpartum follow-up, to support and establish a care plan for each user, through the nursing process using standardized language. Similarly, they suggested that the introductions to each module should be improved with a more motivating text and that the information presented at the main page could be expanded to facilitate access to each module. Flexible software design and SCRUM methodology enabled rapid software adjustments from validation observations.

After the validation process, 33 first-time mothers evaluated the Amacompri software for 4 consecutive months, during which the software obtained mostly high ratings. In the observations the evaluators mentioned that it is an excellent application, easy to use, with very appropriate material to address their concerns, and stated that it was applicable to their experiences as first-time mothers, and that they felt accompanied through a direct communication and easy interaction with the nurse. They eventually expressed that the colors and main menu were appropriate, and the information in each module was clear, didactic and with reliable sources. The only difficulty they encountered was that sometimes the software became slow, but they emphasized that it was due to failures with the internet service of each user.

\section{DISCUSSION}

The use of healthcare technologies is gaining importance due to the lack of postpartum follow-up programs after hospital discharge (14). The Amacompri software has novel educational content and integrates standardized nursing language for postpartum monitoring, which is a contribution in technological innovation to maternal-infant nursing, both for practice and research purposes. 
The expressive writing used in the mother's digital diary helped to elicit the true feelings of the user without the need to fall into an information bias (24). The use of unstructured data such as nursing notes, description of situations, thoughts and behaviors, made it difficult to automate nursing activities such as care plans and responses to situations; however, this experience enabled us to customize responses that gave added value to the accompaniment of the first-time mother.

Gamification was used to create a score of the achievements of mothers, motivating them to carry out activities focused on strengthening social support, affective bonding, maternal self-efficacy for the performance of the role of mother, changing habits and acquiring knowledge through multimedia material and with the follow-up of the nursing professional $(25,26,27)$.

The Amacompri software obtained high ratings in the functional, technical-esthetic and pedagogical aspects, both on validation and evaluation. In other aspects, previous studies have also shown the importance of validating their applications as an opportunity for the target population and experts to give suggestions for a better software version (28).

There are coincidences in the evaluation of first-time mothers in this study with a research conducted in Singapore, which assessed the effectiveness of an educational program based on an application for first-time parents during the postpartum period. They described as beneficial the access to information by audio and video, and the advice of the healthcare professional, and that they did not feel alone (10). Other research has found that the use of technology brings benefits to first-time mothers (29).

The Amacompri software features innovative educational material, which facilitates motivation and easy learning. The use of audiovisuals is recommended to provide education to first-time mothers (30).

On the other hand, the positive evaluation of this software has in common with other studies that its design, development, and application are based on a disciplinary theory $(11,13,31)$. This is consistent with the specific needs of the target audience and with the support provided by nursing (9).

Within the limitations of the software, the lack of operationalization of care plan activities focused on a larger population of new mothers, covering the scale of cities or countries, was found. Then, to consider the scalability and diffusion of the software, new versions of the Amacompri software are expected to use artificial intelligence techniques such as records analysis, natural language processing, and scenario classification for task automation.

Also, using this software in another context requires a cultural adaptation for the proper appropriation of technology as a tool to support care, as well as translation that considers the language variations of each country.

Finally, to improve interoperability aspects, it is recommended to migrate to an microservices architecture that allows integration with other health care information systems and platforms. It is also recommended to analyze the latest standards that support the safe use of clinical systems to apply them in our software. Among them are: Data structure standards (32) such as ISO 18308 requirements for an electronic health record architecture; safety standards $(33,34)$ such as ISO 27799 information security management in health and protection standards (35) such us IEC 82304-1 health software: general requirements for product safety. 


\section{CONCLUSIONS}

The Amacompri software was designed based on Mercer's theory of becoming a mother, and has been technically validated (experts) and validated by population (first mothers), demonstrating its quality in both presentation and content.

Its evaluation demonstrated its effectiveness in meeting the development objective. In this context, the Amacompri software meets multimedia requirements in the functional, technical-esthetic, and pedagogical aspects.

Authors Contribution: "Conceptualization, C.V.P., C.F.G., M.I.M.; Content and data curation and formal analysis, C.V.P., E.C.T.; Acquisition of funds, C.V.P.; Research and Methodology, C.V.P., E.C.T., C.F.G., M.I.M.; Project management and material resources, C.V.P.; Supervision, C.F.G., M.I.M.; Validation and Visualization, C.V.P., E.C.T., C.F.G., M.I.M.; Drafting - original draft, C.V.P., E.C.T.; Drafting - review and editing, C.V.P., E.C.T., C.F.G., M.I.M. All authors have read and accepted the published version of the manuscript."

Funding: None

Acknowledgements. The authors would like to thank the Universidad Industrial de Santander that supported the preparation an operation of the Amacompri software, the Clinica Materno Infantil San Luis (Bucaramanga, Colombia), experts and all mothers for their participation.

Conflicts of interest: The authors declare that there are no conflict of interests.

\section{REFERENCES}

1. Mercer RT. Nursing support of the process of becoming a mother. Journal of obstetric, gynecologic, and neonatal nursing: JOGNN. 2006;35(5):649-51. https://doi.org/10.1111/j.1552-6909.2006.00086.x

2. Meleis A. Becoming a mother versus maternal role attainment. Transitions Theory: middle range and situation specific theories in nursing research and practice. 2010;3:95-102.

3. Nyström K, Öhrling K. Parenthood experiences during the child's first year: literature review. Journal of Advanced Nursing. 2004;46(3):319-30. https://doi.org/10.1111/j.1365-2648.2004.02991.x

4. Pascual CP, Pinedo IA, Grandes G, Cifuentes ME, Inda IG, Gordon JP. Necesidades percibidas por las mujeres respecto a su maternidad. Estudio cualitativo para el rediseño de la educación maternal. Atención Primaria. 2016;48(10):6. https://doi.org/10.1016/j.aprim.2015.12.004

5. Shorey S, Chan WC, Chong YS, He HG. A randomized controlled trial of the effectiveness of a postnatal psychoeducation programme on outcomes of primiparas: study protocol. J Adv Nurs. 2015;71(1):193-203. https://doi.org/10.1111/jan.12461

6. Barbosa EM, Sousa AA, Vasconcelos MG, Carvalho RE, Oria MO, Rodrigues DP. Educational technologies to encourage (self) care in postpartum women. Rev Bras Enferm. 2016;69(3):582-90. https://doi.org/10.1590/0034-7167.2016690323i 
7. Shorey S, Chan SW, Chong YS, He HG. A randomized controlled trial of the effectiveness of a postnatal psychoeducation programme on self-efficacy, social support and postnatal depression among primiparas. J Adv Nurs. 2015;71(6):1260-73. https://doi.org/10.1111/jan.12590

8. Strohbach A, Hu F, Martinez NG, Yee LM. Evaluating the use of text message communication in a postpartum patient navigation program for publicly insured women. Patient Educ Couns. 2019;102(4):753-9. https://doi.org/10.1016/j.pec.2018.10.028

9. Starkweather A, Jacelon CS, Bakken S, Barton DL, DeVito Dabbs A, Dorsey SG, et al. The Use of Technology to Support Precision Health in Nursing Science. J Nurs Scholarsh. 2019;51(6):614-23. https://doi.org/10.1111/jnu.12518

10. Shorey S, Yang YY, Dennis CL. A Mobile Health App-Based Postnatal Educational Program (Homebut not Alone): Descriptive Qualitative Study. J Med Internet Res. 2018;20(4):e119. https://doi.org/10.2196/jmir.9188

11. Shorey S, Chee CYI, Ng ED, Lau Y, Dennis CL, Chan YH. Evaluation of a Technology-Based PeerSupport Intervention Program for Preventing Postnatal Depression (Part 1): Randomized Controlled Trial. J Med Internet Res. 2019;21(8):e12410. https://doi.org/10.2196/12410

12. Shorey S, Ng YPM, Ng ED, Siew AL, Morelius E, Yoong J, et al. Effectiveness of a TechnologyBased Supportive Educational Parenting Program on Parental Outcomes (Part 1): Randomized Controlled Trial. J Med Internet Res. 2019;21(2):e10816. https://doi.org/10.2196/10816

13. Shorey S, Lau Y, Dennis CL, Chan YS, Tam WWS, Chan YH. A randomized-controlled trial to examine the effectiveness of the 'Home-but not Alone' mobile-health application educational programme on parental outcomes. J Adv Nurs. 2017;73(9):2103-17. https://doi.org/10.1111/jan.13293

14. Feroz A, Perveen S, Aftab W. Role of mHealth applications for improving antenatal and postnatal care in low and middle income countries: a systematic review. BMC Health Serv Res. 2017;17(1):704. https://doi.org/10.1186/s12913-017-2664-7

15. Sondaal SF, Browne JL, Amoakoh-Coleman M, Borgstein A, Miltenburg AS, Verwijs M, et al. Assessing the Effect of mHealth Interventions in Improving Maternal and Neonatal Care in Low- and Middle-Income Countries: A Systematic Review. PLoS One. 2016;11(5):e0154664. https://doi.org/10.1371/journal.pone.0154664

16.Alligood M R. Nursing Theorists and Their Work-E-Book: Unit V: Middle Range Theories: Ramona T. Mercer: Maternal Role Attainment-Becoming a Mother. 9th ed: Elsevier Health Sciences; 2018.

17. Mosby. Nursing Theory: Utilization and Application. 5 ed: Elsevier Inc.; 2014.

18.Schwaber K. Agile Project Management with Scrum. Microsoft press. 2004. p.163. https://doi.org/10.1007/11499053_47

19. Leff A, Rayfield JT, editors. Web-application development using the Model/View/Controller design pattern. Proceedings Fifth IEEE International Enterprise Distributed Object Computing Conference; 2001 4-7 Sept. 2001. https://doi.org/10.1109/EDOC.2001.950428

20. Sanson G, Alvaro R, Cocchieri A, Vellone E, Welton J, Maurici M, et al. Nursing Diagnoses, Interventions, and Activities as Described by a Nursing Minimum Data Set: A Prospective Study in an 
Oncology Hospital Setting. Cancer Nurs. 2019;42(2):E39-E47. https://doi.org/10.1097/NCC.0000000000000581

21. Biham E, Chen R, Joux A. Cryptanalysis of SHA-0 and Reduced SHA-1. Journal of Cryptology. 2015;28(1):110-60. https://doi.org/10.1007/s00145-014-9179-8

22. Vargas-Porras C, Roa-Diaz ZM, Hernandez-Hincapie HG, Ferre-Grau C, de Molina-Fernandez MI. Efficacy of a multimodal nursing intervention strategy in the process of becoming a mother: $\mathrm{A}$ randomized controlled trial. Res Nurs Health. 2021;44(3):424-37. https://doi.org/10.1002/nur.22123

23. Marqués P. Ficha de catalogación y evaluación multimedia. Universidad Autónoma de Barcelona: Universidad Autónoma de Barcelona; 2001 [Available from: http://peremarques.pangea.org/evalua.htm]

24. Horowitz S. Evidence-based health outcomes of expressive writing. Alternative and Complementary Therapies. 2008;14(4):194-8. https://doi.org/10.1089/act.2008.14405

25. Viera K, Pardo J, Ben-Abdellah L, Martín S, Ávila J. Gamificación: papel del juego en las aplicaciones digitales en salud. FMC - Formación Médica Continuada en Atención Primaria. 2015;22: 369-374. https://doi.org/10.1016/j.fmc.2015.05.002

26. Bartolomé NA, Zorrilla AM, Zapirain BG, editors. Can game-based therapies be trusted? Is gamebased education effective? A systematic review of the Serious Games for health and education. 2011 16th International Conference on Computer Games (CGAMES); 2011 27-30 July 2011. https://doi.org/10.1109/CGAMES.2011.6000353

27. Ghisays M, Suarez M, Lastre G, Fuentes Y, Orozco S, Schonewolff S, Verdooren K. Nutritional condition or fiveyearold minor children in the colombian caribbean. Ciencia e Innovación en Salud. e62. 2018:1-3. 13. https://doi.org/10.17081/innosa.62

28. Kho SES, Lim SG, Hoi WH, Ng PL, Tan L, Kowitlawakul Y. The Development of a Diabetes Application for Patients With Poorly Controlled Type 2 Diabetes Mellitus. Comput Inform Nurs. 2019;37(2):99-106. https://doi.org/10.1097/CIN.0000000000000485

29. Danbjørg DB, Wagner L, Clemensen J. Designing, Developing, and Testing an App for Parents Being Discharged Early Postnatally. The Journal for Nurse Practitioners. 2014;10(10):794-802. https://doi.org/10.1016/j.nurpra.2014.07.023

30. Emmanuel BC, Ramos RC, Ajuonuma UJ, Ajuonuma MU, Uzo-Ngerem AJ, Ajonuma LC. Effectiveness of New Born Care Programme on Perceived Maternal Competence and Satisfaction of Nigerian Mothers. Available from: https://www.iiste.org/Journals/index.php/JHMN/article/view/36623/37637

31. Foster M. A Mobile Application for Patients With Heart Failure: Theory- and Evidence-Based Design and Testing. Comput Inform Nurs. 2018;36(11):540-9. https://doi.org/10.1097/CIN.0000000000000465

32. Cruz, M., Lastra, N., Lastre-Amell, G. 2018. Review of concepts: pregnancy in adolescents and experience in prenatal control. Ciencia e Innovación en Salud. e62:1-21. https://doi.org/10.17081/innosa.63

33. ISO 18308:2011 Health informatics - Requirements for an electronic health record architecture. [Online]; 2017 [cited 202110 18]. Available from: https://www.iso.org/standard/52823.html. 
34. ISO 27799:2016 Health informatics — Information security management in health using ISO/IEC 27002. [Online]; 2016 [cited 202110 18]. Available from: https://www.iso.org/standard/62777.html.

35. IEC 82304-1:2016 Health software - Part 1: General requirements for product safety. [Online]; 2016 [cited 202110 18]. Available from: https://www.iso.org/standard/59543.html. 